\title{
Treatment of Severe Behavioral Problems in Adults with Intellectual Disabilities
}

\author{
Fabienne Giuliani* \\ Department of Psychiatry, Switzerland
}

Submission: July 30, 2018; Published: August 14, 2018

*Corresponding author: Fabienne Giuliani, Section of Psychiatry of Mental Development, Department of Psychiatry SPDM, Site de Cery, 1008 Prilly, Switzerland. Tel +4121 3142185; E-mail: fabienne.Giuliani@chuv.ch

\begin{abstract}
A significant number of individuals with intellectual disabilities also display serious behavioral problems. These behaviors can be both severely intense and very frequent, and thus require some sort of intervention. We believe that improving the care and medical treatment for this population is essential. As it stands, there is a great disparity in care between these individuals and the general population, and for the following reasons: (1) Limited access to services, (2) Poor quality of care, (3) Lack of professional knowledge in the area of mental disabilities.
\end{abstract}

This article will briefly review the initial results obtained in the care of 420 adult patients with intellectual disabilities and psychiatric comorbidities who were treated in a psychiatric unit specialized in the treatment of this particular population.

Keywords: Intellectual disability; Adulthood ; Severe behavioral problems

\section{Introduction}

The care and treatment of severe behavioral problems in adults with intellectual disabilities is a complex problem. Numerous studies [1-7] have shown that the health needs of individuals with intellectual disabilities are greater and more complicated. In its most recent report on disability, the World Health Organization [8] suggested that these differences may be attributed to a limited access to services and to a poor quality of care. Ouellette-Kuntz et al. [9] have shown that medical students who receive improved supervision when treating patients with intellectual disabilities are much more likely to be favorable to the social inclusion of this group.

According to Wachtel and Hagopian [10], the problematic behaviors of individuals with an intellectual disability have been much considered and studied in recent decades and remain a challenge for health professionals.

Studies conducted on adults with intellectual disabilities have shown a variable prevalence of all problematic behaviors, from $6.1 \%$ in the general community to $40 \%$ in long-term hospitals [11-14]. A prospective study on the incidence of poor mental health in an epidemiological sample of adults with intellectual disabilities found a $4.6 \%$ incidence rate of problematic behaviors over two years [15].

The equifinality of problematic behaviors remains central and most experts agree that severe behavioral problems have multiple determinants $[16,17]$. Numerous studies have shown a high prevalence of severe behavioral problems such as: aggressivity (2-28\%), destructive behaviors (10-31\%), selfharm (7-30\%) [18] and these serious behaviors have a significant impact on social exclusion and long-term hospitalization [19]. These are very worrying behaviors as they have real physical, social, educational and economic consequences [17]. Not only does self-harm and aggression cause physically serious injuries, but they can also lead to understimulation $[17,20]$.

In Switzerland, the accepted diagnostic criteria for serious behavioral problems in adults with intellectual disabilities are the following: (Problem Behavior Severity Scale, PBSSIIR, French version EGCP-IIR) [21]: "A problematic behavior is deemed severe if it actually or potentially places the individual in question, another individual, or the environment, in physical or psychological harm, or if it involves any compromise of the individual's freedom, social integration or relationships."

i. The problematic behavior is significantly frequent, serious, or chronic to the extent that it requires clinical evaluations and interventions or special support;

ii. The problematic behavior should not be a direct consequence of other psychiatric conditions (for example, Autism Spectrum Disorders, non-affective psychotic disorders, depression, generalized anxiety, personality disorder), medicines, or physical disorders; 


\section{Global Journal of Intellectual \& Developmental Disabilities}

iii. One of the following elements must be present:

a. The problematic behavior leads to significant negative repercussions on the quality of life of the individual or of others.

b. The problematic behavior poses significant health and safety risks for the individual or others.

iv. The problematic behavior is persistent and omnipresent.

We studied 420 case files of adults with an intellectual disability and psychiatric comorbidities under care in a psychiatric unit specializing in the treatment of adult mental handicaps. The severe behavioral problems were documented using the French version EGCP-IIR scale (PBSS-IIR) [21], meaning:

i. Stereotypical behaviors

ii. Sexually perverse behaviors

iii. Disturbing social behaviors

iv. Physically aggressive behaviors toward others

v. Socially offensive behaviors

vi. Withdrawal behaviors

vii. Behaviors that are materially destructive

viii. Self-harm behaviors

ix. Non-cooperative and provocative behaviors

\section{Conclusion}

The first results of our study show that amongst the 420 individuals with an intellectual disability being treated in our specialized psychiatric department, $63 \%$ were men. The average age was 37.6 +/- 0.59. The Global Assessment of Functioning [22] was 50.6, meaning that there was a significant occurrence of the following symptoms: suicidal ideation, severe obsessive rituals and significant handicap in social functioning. $24 \%$ of our sample did not have any severe behavioral problems but did present psychiatric comorbidities. 320 adults with intellectual disabilities presented with severe behavioral problems, a total of $76 \%$. For this category we reported a majority of aggressive-type behaviors (aggressive, destructive, provocative, sexual, offensive and disturbing (70\%); self-mutilation and stereotypical (19\%), and withdrawal $(11 \%)$ were a minority. Our results were in line with several other studies [1,4-7,18-19,23-26].

We note that in Switzerland, like many other countries, a large majority of health professionals are hesitant to treat individuals with intellectual disabilities $[1,27,28]$. Insufficient training [29,30], a lack of time by professionals [31] and a poor access to services for this population may be responsible for the decline in mental health of adults with intellectual disabilities.

\section{Acknowledgement}

The study is currently undergoing statistical analyses, and this is being done by our colleague, Mr. Medhi Mohammad Gholamrezaee, a statistician at the CHUV.

\section{Conflict of Interest}

The author declares there are no economic interests or any conflicts of interests.

\section{References}

1. Morin D, Valois P, Crocker AG, Robitaille C, Lopes T (2018) Attitudes of health care professionals toward people with intellectual disability: a comparison with the general population. Journal of intellectual disability research.

2. Cooper SA, Mc Connachie A, Allan LM, Melville C, Smiley E, et al. (2011) Neighbourhood deprivation, health inequalities and service access by adults with intellectual disabilities: a cross-sectional study. Journal of intellectual disability research 55(3): 313-323.

3. Nicholson L, Cooper SA (2011) Access to healthcare services by people with intellectual disabilities: a rural-urban comparison. J of Intellect Disabi 15(2): 115-330.

4. Carey IM, Hosking FJ, DeWilde S, Harris T, Beighton C, et al. (2016) Learning disability registers in primary care. Br J Gen Pract 66(648): 351-352.

5. Carey IM, Hosking FJ, Harris T, DeWilde S, Beighton C, et al. (2017) Do health checks for adults with intellectual disability reduce emergency hospital admissions? Evaluation of a natural experiment. J Epidemiol Community Health. 71(1): 52-58.

6. Carey IM, Shah SM, Hosking FJ, DeWilde S, Harris T, et al. (2016) Health characteristics and consultation patterns of people with intellectual disability: a cross-sectional database study in English general practice. Br J Gen Pract 66(645): e264-270.

7. Hosking FJ, Carey IM, Shah SM, Harris T, DeWilde S, et al. (2016) Mortality Among Adults With Intellectual Disability in England: Comparisons With the General Population. Am J Public Health. 106(8): 1483-1490.

8. Organization WH. World report on disability (2011).

9. Ouellette Kuntz H, Burge P, Cleaver S, Isaacs B, Lunsky Y, et al. (2012) Attitudes of medical clerks toward persons with intellectual disabilities. Can Fam Physician 58(5): e282-288.

10. Wachtel LE, Hagopian LP (2006) Psychopharmacology and applied behavioral analysis: tandem treatment of severe problem behaviors in intellectual disability and a case series. Isr J Psychiatry Relat Sci. 43(4): 265-274.

11. Emerson E, Hatton C, Baines S, Robertson J (2016) The physical health of British adults with intellectual disability: cross sectional study. Int J Equity Health 15:11.

12. Emerson E, Kiernan C, Alborz A, Reeves D, Mason H, et al. (2001) Predicting the persistence of severe self-injurious behavior. Research in developmental disabilities. 22(1): 67-75.

13. Hatton C, Emerson E, Kieman C (1995) People in institutions in Europe. Ment Retard 33(2): 132.

14. Hatton C, Emerson E, Robertson J, Henderson D, Cooper J (1995) The quality and costs of residential services for adults with multiple disabilities: a comparative evaluation. Res Dev Disabil 16(6): 439-460.

15. Smiley E, Cooper SA, Finlayson J, Jackson A, Allan L, et al (2007) Incidence and predictors of mental ill-health in adults with intellectual disabilities: prospective study. Br J Psychiatry 191: 313-319. 
16. Benson BA, Brooks WT (2008) Aggressive challenging behaviour and intellectual disability. Curr Opin Psychiatry. 21(5): 454-458.

17. Paclawskyj TR, Kurtz PF, O'Connor JT (2004) Functional assessment of problem behaviors in adults with mental retardation. Behav Modif 28(5): 649-667.

18. Borthwick Duffy SA (1994) Epidemiology and prevalence of psychopathology in people with mental retardation. J consult Clin Psychol 62: 17-27.

19. Folch A, Cortes MJ, Salvador Carulla L, Vicens P, Irazabal M, et al (2018) Risk factors and topographies for self-injurious behaviour in a sample of adults with intellectual developmental disorders. Journal of intellectual disability research.

20. Borthwick Duffy SA, Lane KL, Widaman KF (1997) Measuring problem behaviors in children with mental retardation: dimensions and predictors. Res Dev Disabil18(6): 415-433.

21. Sabourin G, Senécal P, Paquet M (2016) EGCP-IIR Échelle d'évaluation globale de la gravité des comportements problématiques II - Révisée. Montreal: SQETGC CIUSSS MCQ.

22. DSM-V, editor. DSM-V. Diagnostic and Statistical Manual of Mental Disorders, 5th Edition. Washington, DC: American Psychiatric Association; 2013.

23. Crocker AG, Mercier C, Allaire JF, Roy ME (2007) Profiles and correlates of aggressive behaviour among adults with intellectual disabilities. Journal of intellectual disability research 51(10): 786-801.

24. Crocker AG, Mercier C, Lachapelle Y, Brunet A, Morin D, et al. (2006) Prevalence and types of aggressive behaviour among adults with intellectual disabilities. J Intellect Disabil Res 50(9): 652-661.
25. Crocker AG, Prokic A, Morin D, Reyes A (2014) Intellectual disability and co-occurring mental health and physical disorders in aggressive behaviour. J Intellect Disabil Res 58(11): 1032-1044.

26. Ali A, Hall I, Blickwedel J, Hassiotis A (2015) Behavioural and cognitive-behavioural interventions for outwardly-directed aggressive behaviour in people with intellectual disabilities. Cochrane Database Syst Rev 18(4): CD003406.

27. Edwards N, Lennox N, White P (2007) Queensland psychiatrists' attitudes and perceptions of adults with intellectual disability. Journal of intellectual disability research 51(1): 75-81.

28. Werner S, Stawski M, Polakiewicz Y, Levav I (2013) Psychiatrists' knowledge, training and attitudes regarding the care of individuals with intellectual disability. Journal of intellectual disability research 57(8): 774-782.

29. Phillips A, Morrison J, Davis RW (2004) General practitioners' educational needs in intellectual disability health. J Intellect Disabil Res a48(2): 142-149.

30. Trollor JN, Ruffell B, Tracy J, Torr JJ, Durvasula S, et al (2016) Intellectual disability health content within medical curriculum: an audit of what our future doctors are taught. BMC Med Educ 16: 105.

31. Tuffrey-Wijne I, Goulding L, Giatras N, Abraham E, Gillard S, et al. (2014) The barriers to and enablers of providing reasonably adjusted health services to people with intellectual disabilities in acute hospitals: evidence from a mixed-methods study. BMJ Open 4(4): e004606

Your next submission with Juniper Publishers will reach you the below assets

- Quality Editorial service

- Swift Peer Review

- Reprints availability

- E-prints Service

- Manuscript Podcast for convenient understanding

- Global attainment for your research

- Manuscript accessibility in different formats

( Pdf, E-pub, Full Text, Audio)

- Unceasing customer service

Track the below URL for one-step submission https://juniperpublishers.com/online-submission.php 